\title{
Precarização do trabalho: a funcionalidade da educação profissional
}

\author{
Precariousness of labor: the function of \\ professional education \\ Precarización del trabajo: la funcionalidad de \\ la educación profesional
}

\begin{abstract}
Ramon de Oliveira
Universidade Federal de Pernambuco, Centro de Educação, Departamento de Fundamentos Sócio-filosóficos da Educação, Recife, PE, Brasil
\end{abstract}

\section{Resumo}

Considerando o crescente número de políticas públicas de qualificação profissional voltadas para a juventude, apresentam-se os resultados de uma pesquisa cujo objetivo foi analisar a forma de inserção da juventude brasileira no mercado de trabalho. Tendo como movimento metodológico a análise dos programas públicos de qualificação profissional e a análise de dados apresentados pelo Ministério do Trabalho e Emprego e do Departamento

RO: doutor em Educação, e-mail: ramono@elogica.com.br 
Intersindical de Estatística e de Estudos Socioeconômicos (Dieese) e, tendo como aporte teórico a literatura que discute o mercado de trabalho brasileiro e as políticas de juventude, defende-se que as políticas públicas de qualificação profissional, particularmente as voltadas para a juventude, ampliadas no mandato do presidente Lula e continuadas no governo Dilma, ao pautarem-se pelo desenvolvimento de competências laborais, pelo fortalecimento da empregabilidade e pelo objetivo de formar sujeitos empreendedores, reforçam a ideologia da meritocracia, bem como individualizam o enfrentamento ao problema do desemprego, retirando do Estado o compromisso social e político de enfrentamento à lógica desestruturante do capital. Conclui-se que essas políticas articulam-se diretamente à má qualidade da escola pública e convertem-se em instrumentos funcionais ao processo de reprodução do capital e de acirramento dos processos de exploração dos trabalhadores, direcionando-se basicamente à formação de uma mão de obra capaz de adequar-se subjetiva e tecnicamente a postos de trabalho precarizados.

Palavras-chave: Qualificação profissional. Precarização do trabalho. Desemprego.

\section{Abstract}

Taking into account the growing number of public policies on professional qualification concerning youth, we present the results of a research whose target was to analyze the ways of integration Brazilian youngsters in wok market. Having as a methodological strategy the analyze of professional qualification political programs and data analyze published by the Work Ministry and the Inter-tradeunionist of Statistics and Socioeconomical Studies (Dieese) and having as theoretical approach the literature on Brazilian wok market and the youth policies, it is argued that public professional qualification policies, particularly the youth oriented ones, deepened in Lula's and kept on in Dilmas' government, once based on the development of labor competencies aiming at both strengthening employability and forming entrepreneurs, reinforces meritocratic ideologies as well as individualizes the way of coping with problems related to unemployment, therefore, exempts the State from its social and political responsibility to cope with capitalism unstructured logic. We have concluded that such policy is directly articulated with bad public school quality and compose a functional bloc with the capital 
reproduction process and intensification of worker exploitation; aiming, basically, subjective and technical adjustment of labor force to precarious job positions.

Keywords: Professional qualification. Precariousness of labor. Unemployment.

\section{Resumen}

Considerando el creciente número de políticas públicas de cualificación profesional dirigidas a la juventud, se presentan los resultados de una investigación cuyo objetivo fue analisar la manera de inserción de la juventud brasileña en el mercado de trabajo. Teniendo como movimiento metodológico el análisis de los programas públicos de cualificación profesional y el análisis de datos presentados por el ministerio del trabajo y empleo y del Departamento Intersindical de Estadística y de Estudios Socioeconómicos (Dieese) y teniendo como aporte teórico la literatura que discute el mercado de trabajo brasileño y las políticas para la juventud, se defiende que las políticas públicas de cualificación profesional, notadamente las dirigidas para la juventud, ampliadas en el gobierno del presidente Lula y continuadas en el gobierno Dilma, al presentaren como eje el desarrollo de competencias laborales, el fortalecimiento de la capacidad de conseguir un trabajo y el objetivo de formar sujetos emprendedores, refuerzan la ideología de la meritocracia, así como individualizan el enfretamiento al problema del paro, quitando del Estado el compromiso social y político de enfrentamiento a la lógica desestruturante del capital. Se puede concluir que estas políticas se relacionan directamente a la mala calidad de la escuela pública y componen un bloque funcional al processo de reproducción del capital e de fortalecimiento de los procesos de explotación de los trabajadores, dirigíndose basicamente a la formación de una mano de obra capaz de adecuarse subjetiva y tecnicamente a los trabajos precarizados.

Palabras Clave: Cualificación professional. Precarización del trabajo. Paro.

\section{Introdução}

O Brasil e praticamente todas as nações latino-americanas implementaram reformas em seus sistemas de educação ou em suas ações 
de qualificação profissional, objetivando adequá-los às demandas evidenciadas pelo patronato (OLIVEIRA, 2010a). Destaque-se o quanto essas medidas, aliadas ao processo de globalização econômica e de aumento da competitividade, assumiram a pedagogia das competências como carro-chefe de seus processos formativos, estruturando no campo da formação profissional um consenso semelhante ao do campo econômico (Gentili, 1998). As nações latino-americanas implementaram no plano educacional projetos similares, levando-nos a questionar o quanto suas políticas educacionais estruturam-se de forma autônoma. Parece-nos que elas subordinam-se a referenciais externos, particularmente às determinações de organizações multilaterais como o Banco Mundial e o Banco Interamericano de Desenvolvimento (Bird) (OLIVEIRA, 2006).

Diante de um número cada vez menor de postos de trabalho criados, efetivou-se o discurso hegemônico de defesa da empregabilidade dos trabalhadores. Mesmo destacando-se a importância da educação escolar como componente fundamental no desenvolvimento do capital humano, reconhece-se que a certificação escolar não é garantia de emprego, principalmente para os setores com baixos níveis de escolarização ou considerados não detentores das habilidades, das competências e dos conhecimentos requisitados pelo mercado de trabalho.

No discurso das elites empresariais, dos agentes de governo e das agências multilaterais, a baixa qualidade da mão de obra, em vez de ser tratada como decorrência de um processo histórico de exploração econômica, é explicada como uma debilidade da escola pública e das práticas de qualificação profissional (INSTITUTO HERBERT LEVY, 1992). Assim, o determinante torna-se determinado, tal como nos alertava Frigotto (1989) ao fazer uma crítica profunda à teoria do capital humano.

Essa teoria, bem como suas atuais formas de expressão, encobre o fato de as históricas subalternidades (política, econômica e cultural) vivenciadas por muitas nações terem gerado elementos impeditivos à formação de trabalhadores mais qualificados, aptos a enfrentarem os desafios postos pelas transformações advindas da reestruturação da produção capitalista. As nações mais pobres apresentam índices educacionais bem 
aquém daqueles considerados indispensáveis para uma economia nacional disputar uma melhor posição na competição global.

A forma de participação de cada nação na divisão internacional do trabalho determinará a necessidade e a pertinência da existência de maior estoque de mão de obra qualificada para a produção de bens com maior valor agregado. Não é o processo de formação de capital humano o responsável, em primeira instância, por essa inserção, e muito menos a inserção como protagonista constrói-se desconsiderando relações de poder condicionantes das formas de participação de algumas economias nacionais no processo de mundialização do capital (CHESNAIS, 1996).

Como destacou Pochmann (2001), as corporações têm deslocado sua capacidade produtiva pelo mundo visando aumentar seus níveis de acumulação. No entanto, esse processo não é acompanhado da transferência, para as nações mais pobres, das atividades de maior complexidade industrial, muito menos a riqueza abocanhada pelo capital desconcentra-se e canaliza-se para atender aos interesses das nações receptoras dessa produção. Na prática, o capital mantém inalterada a concentração da riqueza e estabelece mecanismos reforçadores das desigualdades econômicas e sociais que afligem as nações periféricas ou semiperiféricas.

Tendo esse cenário e esses pressupostos como referências, demonstraremos o quanto as práticas de formação profissional, particularmente aquelas voltadas para a juventude, funcionam como mecanismos de conformação de trabalhadores à lógica do capital. Embora tais políticas busquem justificar-se pelo aumento da empregabilidade dos trabalhadores e pelo fomento de práticas empreendedoras, tornam-se também funcionais ao capital por terem um papel ativo de formação de trabalhadores para a ocupação de postos precarizados.

Consideramos que as políticas públicas de qualificação profissional voltadas para os setores juvenis em condições econômicas precarizadas vinculam-se diretamente à má qualidade da escola pública, e convertem-se em instrumentos funcionais ao processo de reprodução do capital e de acirramento dos processos de exploração dos trabalhadores. 
Metodologicamente, desenvolvemos um levantamento de dados contidos nos anuários dos trabalhadores ${ }^{1}$ produzidos pelo Departamento Intersindical de Estatística e Estudos Socioeconômicos (Dieese) e daqueles divulgados pelo Ministério do Trabalho e Emprego que pudessem nos ajudar a compreender o movimento de inserção dos jovens no mercado de trabalho.

\section{Empregabilidade, empreendedorismo e educação profissional}

Como nos alertou Antunes (2002), uma análise consequente do desemprego, tendo como referências a globalização da economia e a reestruturação produtiva, deve levar em consideração as peculiaridades de cada economia nacional. Caso contrário, deixaremos de lado fatores imprescindíveis para melhor apontar as possibilidades de reversão de um quadro generalizado de desemprego, com situações particulares em cada nação.

Alguns dados colhidos por Pochmann (2001) nos ajudam a ilustrar essa afirmação. De acordo com esse autor, embora o desemprego seja um fenômeno mundial, concentra-se nas nações mais pobres.

Considerando as três décadas finais do século XX, é possível constatar que, entre 1975 e 1999, o desemprego cresceu 53\% em quase todo o mundo, mas, nos países mais pobres, essa taxa foi de $200 \%$. Nesse mesmo período, o número de desempregados cresceu $85 \%$ nos países desenvolvidos, já nos não desenvolvidos esse percentual chegou a 390\%.

Tal situação levou a uma sensível alteração da distribuição geográfica dos desempregados. Em 1975, os países desenvolvidos abrigavam 41\% do total de desempregados do mundo e, em 1979, reduziram essa participação para $20 \%$. Do outro lado, no mesmo período, os países não desenvolvidos abrigavam $59 \%$ e passaram a ser responsáveis por $79,4 \%$ dos desempregados.

Esses dados, embora careçam de atualização cronológica, evidenciam o fato de o desemprego ser heterogêneo, nutrindo e complexificando ainda mais os processos de subordinação e dependência econômica

1 Disponível em: <http://www.dieese.org.br/>. 
de muitas nações. Por outro lado, reforçam a tese de ser impertinente buscar soluções únicas ou saídas que não ataquem diretamente os principais motivos da diminuição dos postos de trabalho.

$\mathrm{Na}$ maioria das vezes, as medidas tomadas reforçam o desemprego e ocultam o quanto os governos têm sido coniventes e responsáveis pela perpetuação desse quadro.

A lógica neoliberal entende o desemprego como normal na economia capitalista e o utiliza para diminuir a força do movimento sindical. Logo, o desemprego, segundo os homens de negócio, não deve mobilizar o Estado para a confecção de políticas sociais ou de reformas estruturais objetivando atenuar seus efeitos sociais. Para eles, cabe ao Estado, na ausência ou no desinteresse da iniciativa privada, a implementação de ações de melhoria da qualificação dos trabalhadores.

As práticas de qualificação profissional têm certo caráter assistencial, pois elas procuram dar ao indivíduo apenas o necessário para, talvez, atenuar seu sofrimento. No entanto, as políticas governamentais nesse campo não conseguem diminuir o quadro de insegurança em que vivem os trabalhadores. Insegurança, segundo Frigotto (2001), por viverem uma contínua diminuição da estabilidade no emprego e terem de obrigar-se a se submeter a relações precárias de trabalho.

Behring (2001), a partir de Jorge Matoso, também destaca a insegurança dos trabalhadores. Sua observação ajuda-nos, tal como Frigotto (2001), a perceber que as ações do capital objetivando aumentar suas taxas de acumulação, tais como a desregulação do mercado de trabalho, a diminuição do papel do Estado como provedor de serviços sociais e, principalmente, a reestruturação do processo de produção de mercadorias, impõem aos trabalhadores uma contínua situação de instabilidade emocional.

No âmbito desse quadro de insegurança, as políticas de qualificação profissional, seja no governo Fernando Henrique, seja no governo Lula, afirmaram-se como apologetas do desenvolvimento de competências laborais e do aumento da empregabilidade dos trabalhadores. Estabeleceram uma relação de independência entre o acesso, a permanência e a qualidade da escola em relação às condições de desigualdade social. 
Condições essas responsáveis pelo Brasil apresentar um nível de escolarização bem abaixo do considerado, segundo o próprio discurso do empresariado (OLIVEIRA, 2005), o mínimo necessário para uma nação responder, a contento, aos desafios da competitividade econômica.

Assim, as políticas públicas de qualificação profissional terminaram por, cada vez mais, formar mão de obra para os empregos precários. Ou, como há muito nos alertava Maria Ciavatta Franco (1999), formam mão de obra para um trabalho incerto.

Como destacou Oliveira (2010b), os pressupostos norteadores da educação profissional "blindam" o Estado de críticas em relação à sua incompetência e conivência com a falta de uma ação efetiva para a geração de postos de trabalho e para a diminuição radical do quadro de pobreza.

Tal fato reforça a posição dos propagadores da ideologia da meritocracia e da individualização da condição social.

\section{A educação profissional $X$ a precarização do trabalho}

Analisando as políticas públicas de qualificação (PLANFOR, PNQ etc. $)^{2}$, evidencia-se o fato de elas atingirem mais diretamente aqueles setores da sociedade inseridos no mercado de trabalho em uma das diversas formas precarizadas impostas pela lógica de acumulação capitalista. A juventude tem sido eleita como público-alvo.

2 O Plano Nacional de Formação Profissional (Planfor) representou o conjunto de ações desencadeadas a partir de 1995 pelo então Ministério do Trabalho (hoje Ministério do Trabalho e Emprego MTE), objetivando garantir, a partir de uma ação coordenada em nível nacional, o incremento da competitividade da indústria nacional e possibilitar aos trabalhadores desempregados ou em risco de marginalidade social desfrutar de ações de qualificação profissional que lhes permitissem permanecer no mercado de trabalho, ou retornar a ele. Objetivou-se, em seu início, a qualificação de cerca de 15 milhões de trabalhadores anualmente, o que representaria $20 \%$ da população economicamente ativa no Brasil (BRASIL, 1998). Em 2003, após seu fim, foi criado o Plano Nacional de Qualificação (PNQ), que passou a orientar as diretrizes da Política Pública de Qualificação. 
Algumas políticas direcionadas para a juventude no governo Lula inseriram a questão da qualificação profissional como um de seus eixos estruturadores. No âmbito governamental, a problemática da juventude ainda é considerada do ponto de vista da inserção econômica. Em outras palavras, a violência, a inserção no mundo do tráfico de drogas, males que afligem a juventude, podem ser combatidos quando os jovens tiverem acesso a algum tipo de instrumentação asseguradora de sua inserção no mercado de trabalho.

A realidade parece demonstrar não ser suficiente instituir políticas de qualificação profissional, ou mesmo políticas visando à geração de renda, para reduzir, de forma mais sistemática, o desemprego juvenil ou pôr fim às condições de pobreza, persistentes para parte da população brasileira. Embora essas políticas sejam fundamentais, precisam estar articuladas entre si. Os males que afetam a juventude são os mesmos por meio dos quais se reproduz a condição de pobreza.

Por outro lado, embora estejamos acostumados a falar em desemprego juvenil, a verdade é que os jovens - muitas vezes precocemente - estão inseridos no mercado de trabalho. Presenciamos a continuidade de uma procura por emprego com certa precocidade por parte dos jovens, mesmo que essa entrada corresponda a sacrificar a conclusão da Educação Básica. Nunca é demais lembrar que, de acordo com a Pesquisa Nacional por Amostra de Domicílios (PNAD) de 2010, 46,7\% dos jovens entre 18 e 24 anos não estavam estudando, só trabalhavam, e 33,3\% deles abandonaram a escola sem ter concluído o Ensino Médio (IBGE, 2010).

Os jovens de 15 a 24 anos representam um contingente populacional de mais de 33 milhões de pessoas. Desse grupo, cerca de 23 milhões (69\%) fazem parte da população economicamente ativa (DIEESE, 2011b), ou seja, estão trabalhando ou estão em situação de desemprego.

Entre os jovens de 15 a 17 anos, idade ideal para cursar o Ensino Médio, cerca de 4,3 milhões fazem parte da população economicamente ativa, representando um percentual de aproximadamente $42 \%$ de todas as pessoas nessa faixa etária. A frequência líquida no Ensino Médio é de apenas 50,9\% (IBGE, 2010), o que significa dizer que a presença de jovens 
dessa faixa etária no mercado de trabalho, aliada à reprovação e à evasão escolar - esta última determinada, inclusive, pelo ingresso numa ocupação - , são questões a serem enfrentadas de forma a garantir aos jovens brasileiros a conclusão do Ensino Médio na idade ideal.

Embora as condições econômicas e uma certa cultura determinem a entrada dos jovens no mercado de trabalho, entendemos que essa aproximação ocorre de forma precoce e em condições precárias.

São os jovens os mais afetados pelo problema do desemprego. Considerando os grupos etários com ação mais sistemática de procura por emprego, observa-se ser exatamente no grupo mais próximo daquele apto a cursar o Ensino Médio que o nível de desemprego é maior. De acordo com dados do Dieese (2011c) referentes ao ano de 2009, o índice de desemprego nacional entre os jovens de 15 a 19 anos chegou a $22,9 \%$, duas vezes maior que no grupo etário entre 25 e 29 anos e três vezes maior que na faixa etária entre 30 e 39 anos. Citamos esses exemplos, mas, comparando com outras faixas, a disparidade é muito maior.

Quando observamos dados mais específicos para o grupo na faixa etária entre 15 e 17 anos, constatamos o quanto a situação de desemprego é muito mais aguda. O caso do Distrito Federal foi, entre as áreas pesquisadas pelo IBGE, a situação mais problemática. Seu índice de desemprego para os jovens nessa faixa etária chegou, em 2010, a quase $65 \%$. Com relação às outras regiões metropolitanas pesquisadas - Recife, São Paulo, Porto Alegre, Belo Horizonte, Salvador, Recife e Fortaleza —, só em Fortaleza e Porto Alegre esse percentual foi inferior a 40\% (28,2\% e $30,2 \%$, respectivamente).

Entre os vários programas voltados para a juventude criados no governo Lula e mantidos pela presidenta Dilma, alguns contemplaram a questão da qualificação/educação profissional como carro-chefe. Destacamos entre esses: ProJovem, Agente Jovem, Saberes da Terra, Consórcio Social da Juventude, Escola de Fábrica, Primeiro Emprego, Soldado Cidadão, Proeja e, mais recentemente, Pronatec.

A diversidade de programas e a prevalência do entendimento da educação como instrumental de amenização da pobreza e da 
marginalidade social evidenciam que a lógica estruturante dos programas governamentais relacionando juventude e "mundo do trabalho" é a mesma das agências de financiamento (Banco Mundial e Banco Interamericano de Desenvolvimento) (OLIVEIRA, 2006). Ou seja, a pobreza reverte-se pelo aumento de escolarização ou pelo desencadeamento de ações públicas de qualificação profissional.

A teoria do capital humano parece ser o eixo filosófico dos programas e das políticas de educação profissional voltadas para a juventude. Castro (2004) chama atenção ao fato de que, a despeito da complexidade da relação entre educação e emprego, é ilusório estabelecer uma relação direta entre o aumento do nível de escolarização da população e a diminuição dos índices de desemprego. Essa ilusão ocorre em virtude de essa interpretação concentrar a atenção no movimento do mercado de trabalho e desprezar a regressão dos postos de trabalho ocorrida no processo recente de acumulação capitalista.

Pochmann (2008) reafirma o quanto se mantém impertinente o discurso sobrevalorizador da educação como mecanismo de contenção dos altos índices de desemprego. Tendo como referência dados relativos aos primeiros anos do século XXI, o autor destaca a "anomalia" de nosso mercado de trabalho, pois mesmo diante de um crescimento do nível de escolaridade da população brasileira, não se criaram as condições viabilizadoras para o aproveitamento daqueles com maior escolarização.

Contrariando as tendências mundiais, que exigem ampliação da escolaridade e maior qualificação profissional no combate ao desemprego, no Brasil a ociosidade da força de trabalho vem aumentando justamente no segmento da população com mais anos de estudo: em 2004, 60,2\% dos desempregados (8,3 milhões de pessoas) possuíam o ensino básico completo, enquanto em 1995 apenas 37,7\% do total dos desempregados (4,5 milhões) tinham até oito anos de estudo. Apesar disso, constata-se uma importante elevação no nível de escolaridade em praticamente todas as faixas etárias. Em 2004, por exemplo, a população brasileira tinha em média 6,6 anos de estudo, enquanto em 1993 eram somente 5,1 anos. Ou seja, houve um aumento de quase $30 \%$ na quantidade de anos de estudo pelo conjunto da população (POCHMANN, 2008, p. 39-40). 
Utilizando dados mais recentes, podemos melhor ilustrar e confirmar essas afirmações de Pochmann (2008). De acordo com o Anuário do Sistema Público de Emprego, Trabalho e Renda 2010/2011 (DIEESE, 2011a), o Sistema Nacional de Emprego (Sine) no ano de 2010 disponibilizou aos trabalhadores em busca de emprego um pouco mais de 2,5 milhões de vagas em todo o Brasil. Para o preenchimento dessas vagas, constatamos que as exigências de escolarização não foram tão elevadas, uma vez que $68,5 \%$ delas sequer requeriam a conclusão do Ensino Médio. No entanto, no momento de contratação dos trabalhadores encaminhados pelo Sine, o processo de seleção determinou o aproveitamento de 47,7\% de trabalhadores com Ensino Médio completo, os quais, juntando-se aos trabalhadores com Ensino Superior completo, compõem um quantitativo de 49,8\%. Ou seja, no momento de seleção, em função de a oferta de trabalhadores com Ensino Médio completo ser superior a 50\%, os empregadores puderam dar-se ao luxo de estabelecer a exigência de níveis de escolarização bem superiores ao demandado pela atividade a ser executada e definidos por eles mesmos quando fizeram solicitação ao Sine.

O mesmo documento nos permite observar que, a despeito de se falar da necessidade de termos trabalhadores mais qualificados, em virtude das novas exigências postas pelo processo de globalização e de reestruturação produtiva, as ocupações mais geradoras de empregos não demandam alta escolarização, algo coerente com o perfil das vagas disponibilizadas pelo Sine (Tabela 1). Segundo esse relatório, dentre as principais ocupações geradoras de emprego e também dentre as quais o Sine conseguiu obter o maior nível de colocação de trabalhadores, destacaram-se: oficial de serviços gerais, trabalhador rural, operador de telemarketing, servente de obras, auxiliar de limpeza, pedreiro, operador de caixa, atendente de lanchonete, porteiro, auxiliar de serviços gerais, ajudante de obras, ajudante de carga e descarga. O perfil dessas ocupações não justifica a exigência de maior escolarização ou de experiência prévia.

Temos, de fato, maior oferta de trabalhadores disponíveis com maior nível de escolarização, permitindo aos empregadores estabelecerem 
novos critérios de seleção no momento real de fazer a contratação, tal qual nos alertou Márcio Pochmann (2008).

Retomando o debate sobre as políticas públicas de qualificação profissional, sem termos a pretensão de discutir os programas governamentais, objetivamos destacar o fato de a maioria deles objetivar proporcionar, aos setores de alguma forma excluídos da Educação Básica, uma nova inserção no sistema educacional. Em outras palavras, esses programas têm um nítido apelo pela inclusão social, seja por garantir o término do Ensino Fundamental, seja por garantir uma qualificação básica, seja pela oferta de ajuda financeira. A Educação Básica (ou Profissional) é tratada como mecanismo capaz de possibilitar uma nova inserção social do indivíduo. Precisamos discutir qual é a forma de inserção no mercado ou na sociedade construída por esses programas.

Tabela 1 - Comparativo entre oferta de vagas do Sine, inscritos no Sine, encaminhamentos e trabalhadores colocados pelo Sine considerando a escolaridade (2010)

\begin{tabular}{lccc}
\hline \multicolumn{1}{c}{ Escolaridade } & Vagas & Inscritos & Colocados \\
\hline Analfabeto & 18,9 & 0,7 & 0,9 \\
\hline Ens. Fund. 1 incompleto & 8,8 & 5,7 & 5,5 \\
\hline Ens. Fund. 1 completo & 6,1 & 4,9 & 5,0 \\
\hline Ens. Fund. 2 incompleto & 8,6 & 13,5 & 12,9 \\
\hline Ens. Fund. 2 completo & 18,5 & 9,1 & 11,1 \\
\hline Ens. Médio incompleto & 7,6 & 16,1 & 14,8 \\
\hline Ens. Médio completo & 30,1 & 39,5 & 42,7 \\
\hline Ens. Sup. incompleto & 0,7 & 6,0 & 5,0 \\
\hline Ens. Sup. completo & 0,6 & 4,6 & 2,1 \\
\hline
\end{tabular}

Fonte: Adaptado de DIEESE, 2011a. 
São programas cujo objetivo é modificar a situação de precarização social vivenciada por esses indivíduos, mas eles se constituem como programas promotores de formas precarizadas de formação. Embora objetivem mudanças nas condições sociais dos jovens por eles assistidos, reforçam a lógica de precarização social imposta à maioria da população mais pobre.

Essa nossa tese ancora-se no fato de os programas voltados à qualificação de jovens não conseguirem confrontar-se com a precária formação ministrada no âmbito da Educação Básica. Ao pautar-se pelo objetivo de promover uma pseudoformação profissional, de certa forma reconhecem a impossibilidade de aprofundamento dessa qualificação, em virtude de os educandos não disporem de conhecimentos básicos necessários para tal formação ter maior complexidade. Por outro lado, tal como vem instituindo-se na Educação Básica, a ênfase em garantir a certificação em detrimento de assegurar uma formação de melhor qualidade tem sido uma das características das ações de qualificação profissional.

O caso do PNQ é uma boa expressão de uma ação que não consegue ir além da mera certificação em detrimento da garantia de uma qualificação profissional articulada à formação geral. Daí seus programas terem, apenas em 2007, atingido uma carga horária média de 200 horas (DIEESE, 2011c).

A crítica a esse descuido com a formação geral não é à toa. De acordo com os dados do Dieese, cerca de $50 \%$ da população economicamente ativa no Brasil têm como escolaridade máxima o Ensino Fundamental, incluindo entre esses muitos sem instrução. Por outro lado, mais de 56\% dos matriculados nos cursos promovidos pelo PNQ não tinham o Ensino Médio completo.

O privilegiamento de uma formação mais pragmática, em detrimento de uma formação mais complexa, é proposital. Semelhantemente a outros programas governamentais, busca-se a mínima formação necessária para esses trabalhadores inserirem-se no mercado de trabalho, de forma a suprir as necessidades do capital para a realização de tarefas de pouca complexidade, mas fundamentais ao processo geral de produção capitalista e de acumulação do capital. 
Parece-nos pertinente a afirmação de haver, para o capital, uma relação funcional entre a precariedade da Educação Básica e os programas de qualificação profissional. Na prática, estabelece-se no plano da formação profissional e do mercado de trabalho um movimento de inclusão excludente, tão bem destacado por Kuenzer (2007).

A baixa escolarização ou a chamada "desqualificação profissional" são expressões de um sistema produtor e alimentado pela desigualdade social e, ao mesmo tempo, funcionais a ele. Como destacou Kuenzer (2007), estrutura-se uma exclusão includente, pois os estudantes mais pobres continuam sendo expulsos das escolas públicas, restando-lhes a alternativa de ingressarem nos programas governamentais como forma de almejar a aquisição de conhecimentos ou certificações que os permita ingressar no mercado de trabalho.

A estratégia por meio da qual o conhecimento é disponibilizado/negado, segundo as necessidades desiguais e diferenciadas dos processos de trabalho integrados, é o que temos chamado de inclusão excludente na ponta da escola. Ao invés da explícita negação das oportunidades de acesso à educação continuada e de qualidade, há uma aparente disponibilização das oportunidades educacionais, por meio de múltiplas modalidades e diferentes naturezas, que se caracterizam por seu caráter desigual e, na maioria das vezes, meramente certificatório, que não asseguram domínio de conhecimentos necessários ao desenvolvimento de competências cognitivas complexas vinculadas à autonomia intelectual, ética e estética (KUENZER, 2007, p. 1167).

A forma de inserção patrocinada por esses cursos ou programas governamentais ocorre, em sua maioria, em postos precarizados de trabalho. Eles não garantem direitos trabalhistas e, de forma alguma, possibilitam que esses trabalhadores usufruam de direitos sociais, bem como tenham acesso a bens materiais e não materiais fundamentais a uma vida com dignidade. Isso nos leva a afirmar que as políticas atuais voltadas para os setores juvenis reforçam o processo de precarização do trabalho.

A presença do trabalho precarizado, contraditoriamente à forte presença de artefatos tecnológicos no processo de produção de 
mercadoria, ou mesmo no setor terciário, não tem se mostrado como algo anômalo à produção flexível ou às formas tradicionais de emprego de mão de obra. Ao contrário, a coexistência, na cadeia produtiva, de trabalhadores com níveis profundamente diferenciados de formação mostra-se bastante funcional ao processo de reprodução do capital. Na verdade, podemos dizer que, no Brasil, contrariamente aos reclamos do empresariado, a Educação Básica de baixa qualidade não tem sido empecilho ao aumento das taxas de acumulação.

O capital não tem a menor resistência em reinstaurar formas aviltantes de utilização da mão de obra, desde que isso possa aumentar a extração de mais-valia e recompor suas taxas de acumulação.

A inserção do trabalhador no mercado de trabalho define-se em função dos interesses e das demandas dos empregadores. Sua qualificação, se é um elemento importante no processo de ingresso, não é determinante. A pura e simples defesa de políticas ou ações de qualificação, como forma de solucionar o problema do desemprego, termina por servir apenas para culpabilizar as vítimas do processo de desemprego e também para ocultar o movimento histórico do capital de diminuir sua dependência em relação ao emprego da força de trabalho.

Quando nos apropriamos de dados relativos à forma como os jovens estão inseridos no mercado de trabalho, as afirmações anteriormente colocadas neste texto passam a ter um pouco mais de sentido.

De acordo com Anuário do Sistema Público de Emprego, Trabalho e Renda 2010/2011, a proporção de jovens de 16 a 24 anos sem carteira assinada em relação ao total de jovens ocupados nessa mesma faixa etária chegou a mais de $37 \%$ no ano de 2009. Se considerarmos que mais de um terço dos jovens estão empregados sem carteira assinada e 56,7\% dos que possuem o Ensino Fundamental mas não concluíram o Ensino Médio recebem até um salário-mínimo (DIEESE, 2011a), não é difícil presumir o quanto os jovens sem conclusão do Ensino Médio representam uma parte considerável da mão de obra extremamente precarizada.

Outro ponto merecedor de destaque é o contingente de jovens entre 15 e 24 anos evadidos da escola. Cerca de 17 milhões de jovens estão 
nessa situação. Alguns não concluíram o Ensino Fundamental, e muitos, o Ensino Médio. Interessa-nos destacar o fato de eles serem o alvo dos programas do Governo Federal. De acordo com o cadastro do ProJovem Trabalhador (DIEESE, 2011a), 63,1\% de seus participantes estavam na faixa etária entre 18 e 24 anos. Em 2009 (IBGE, 2010), por exemplo, 46,7\% dos jovens nessa faixa etária só trabalhavam. Ou seja, os jovens que deveriam estar na universidade são aqueles que, em função da condição de pobreza, são obrigados a buscar tais programas como saída, pois iludem-se com a possibilidade de arranjarem um emprego com salário digno e respeitador dos direitos trabalhistas.

Embora nos últimos anos o nível de desemprego tenha sofrido uma diminuição, ainda é muito expressiva a quantidade de jovens à procura de emprego e sem sucesso. Isso ainda é mais acentuado para os jovens na faixa etária entre 16 e 17 anos, tendo esse percentual chegado, no ano de 2010, a mais de 43\%. Esses dados nos alertam ao fato de que quase metade dos jovens, em vez de estarem concentrados no término da Educação Básica, vislumbrando a inserção no Ensino Superior público, já se voltaram para o mercado de trabalho como forma de garantir seu sustento e o de seus familiares.

Há, de fato, uma disputa entre o mercado de trabalho e a escola. Em muitos casos, a necessidade econômica vem em primeiro lugar.

A Tabela 2 sintetiza a situação dos jovens em relação ao mercado de trabalho em duas regiões metropolitanas (São Paulo e Recife) e nos mostra o quanto, no momento em que há maior oferta de empregos para esses jovens, eles terminam por abandonar a escola. No caso exemplificado, a cidade de São Paulo, em 2010, teve um índice de desemprego para os jovens entre 18 e 24 anos igual a 20,5\%, enquanto em Recife esse índice foi de $32,2 \%$. Como consequência, a quantidade de jovens que só estudavam foi bem maior em Recife, provavelmente não em virtude de melhores escolas, mas em função da menor oportunidade de empregos. A saída dos jovens da escola, determinada, entre outros fatores, por sua má qualidade e pelas condições socioeconômicas desses indivíduos, são fatores que os empurram precocemente para o mercado de trabalho. 
Tabela 2 - Situação dos jovens (16 a 24 anos) em relação a trabalho e estudo regiões metropolitanas (2010)

\begin{tabular}{lcc}
\hline Situação de estudo e trabalho & Recife (\%) & São Paulo (\%) \\
\hline Só estuda & 26,5 & 13,9 \\
\hline Estuda e trabalha & 19,4 & 24,5 \\
\hline Só trabalha & 39,3 & 51,6 \\
\hline
\end{tabular}

Fonte: DIEESE, 2011d.

Os jovens não serão empregados em locais que lhes garantam direitos trabalhistas e bons salários. Muito pelo contrário. Não só lhes serão negados esses direitos, como eles também terão dificuldades de continuarem os estudos. Aumenta anualmente o contingente de jovens não detentores de certificação do Ensino Médio e que encontram em cursos rápidos e precários a "saída mágica" para melhorar seu status econômico e social.

$\mathrm{Na}$ tentativa de ilustrar essa constatação, direcionamo-nos aos dados relativos à população ocupada no ano de 2009. De acordo com os dados do Dieese, do total de 92,7 milhões de pessoas ocupadas, 6,2 milhões eram jovens de 15 a 19 anos e 11,04 milhões de 20 a 24 anos, perfazendo um total de 17,04 milhões ocupados. Esse total corresponde a $18,7 \%$ do total de ocupados.

Mais da metade dos jovens brasileiros estavam e estão, de alguma forma, inseridos em alguma ocupação ou desempregados. Essa informação não esclarece o tipo de ocupação, uma vez que ela pode ser das mais diversas: empregado com carteira assinada, militar, servidor público, empregado sem carteira assinada, trabalhador doméstico, trabalhador por conta própria etc. Nossa tese é de que uma parte considerável desses jovens, principalmente os não concluintes do Ensino Médio, direcionam-se para ocupações precarizadas. Dedicando atenção aos dados referentes aos empregos formais, podemos avançar na comprovação dessa suposição. 
De acordo com o Dieese, no ano de 2010, tivemos no Brasil cerca de 44 milhões de empregos formais, dos quais só $1 \%$ foi para jovens com até 17 anos e 17,1\% para jovens com idade entre 18 e 24 anos, representando um total de 18,1\% de empregos formais para pessoas com até 24 anos. Transformando esse percentual em números absolutos, chegamos a cerca de oito milhões de jovens. No entanto, como mostramos anteriormente, tivemos em 2009 cerca de 17 milhões de jovens ocupados, significando que nove milhões de jovens estavam/estão na informalidade.

Por mais que muitos desses jovens tenham se tornado trabalhadores autônomos bem-sucedidos, tenham aberto seu próprio negócio via empreendedorismos ou qualquer outra possibilidade de garantir uma renda de forma não precarizada, é muito difícil rejeitar a tese de haver utilização massivamente precarizada dessa mão de obra de acordo com os interesses do capital.

Queremos avançar ainda nessa linha de argumentação chamando atenção ao fato de que, embora a informalidade seja quase sinônimo de precarização do trabalho, isso não quer dizer que essa precarização não ocorra também dentro da formalidade. Ou seja, a carteira assinada não significa garantia das adequadas condições de trabalho. Nesse sentido, destacamos o fato de mais de $6 \%$ dos trabalhadores formais receberem menos de um salário-mínimo e um pouco mais de $27 \%$ receberem entre um salário-mínimo e um salário-mínimo e meio. Se esses dados nos causam um desalento, pois sabemos do pequeno poder de compra do salário-mínimo brasileiro, pior é a informação de que, em 2009, em torno de $30 \%$ dos trabalhadores ocupados receberam menos de um salário-mínimo (DIEESE, 2011d). Talvez muitos desses trabalhadores sejam, exatamente, os jovens que passaram por programas públicos de qualificação profissional e que, em algum momento, foram expulsos da escola pública.

Concluindo, retornamos à nossa tese de que, a despeito do discurso corrente de necessidade de um trabalhador com maior nível de qualificação e de escolarização, tem se mostrado funcional ao capital uma escola pública persistente em distribuir desigualmente o conhecimento historicamente produzido. 
Podemos resumir nossa posição com a afirmação de que a má qualidade da Educação Básica no Brasil e o perfil das políticas públicas voltadas para a juventude, executadas desde o governo FHC e ampliadas no governo Lula, compõem um quadro socioformativo funcional ao processo de reprodução do capital, particularmente no concernente à formação de uma mão de obra capaz de adequar-se subjetiva e funcionalmente aos postos de trabalho precarizados.

\section{Referências}

ANTUNES, R. Trabalho, reestruturação produtiva e algumas repercussões no sindicalismo brasileiro In: ANTUNES, R. (Org.). Neoliberalismo, trabalho e sindicatos: reestruturação produtiva na Inglaterra e no Brasil. 2. ed. São Paulo: Boitempo, 2002. p. $71-84$

BEHRING, E. R. O Brasil e a Mundialização do Capital: privatização, deslocalização e flexibilização das relações de trabalho In: SERRA, R. (Org.). Trabalho e reprodução: enfoques e abordagens. São Paulo: Cortez; Rio de Janeiro: PETRESFSS/UERJ, 2001. p. 107-132.

BRASIL. Ministério do Trabalho. Secretaria de Formação e Desenvolvimento Profissional. Plano Nacional de Educação Profissional: reconstruindo a institucionalidade da educação profissional no Brasil. Brasília: SEFOR/FAT, 1998.

CASTRO, R. P. Escola e mercado: a escola face à institucionalização do desemprego e da precariedade na sociedade colocada ao serviço da economia. Perspectiva, v. 22, n. 1, p. 79-92, jan./jun., 2004.

CHESNAIS, F. A mundialização do capital. São Paulo: Xamã, 1996. 
DEPARTAMENTO INTERSINDICAL DE ESTATÍSTICA E DE ESTUDOS SOCIOECONÔMICOS - DIEESE. Anuário do Sistema Público de Emprego, Trabalho e Renda 2010-2011: intermediação de mão de obra. 3. ed. São Paulo: Dieese, 2011a. Disponível em: <http://www.dieese.org.br/anu/AnuSistPub2010/conteudo/2/ livro/inicio.html〉. Acesso em: 10 jan. 2012.

DEPARTAMENTO INTERSINDICAL DE ESTATÍSTICA E DE ESTUDOS SOCIOECONÔMICOS - DIEESE. Anuário do Sistema Público de Emprego, Trabalho e Renda 2010-2011: mercado de trabalho. 3. ed. São Paulo: Dieese, 2011b. Disponível em: <http://www.dieese.org.br/anu/AnuSistPub2010/conteudo/1/livro/inicio. html>. Acesso em: 10 jan. 2012.

DEPARTAMENTO INTERSINDICAL DE ESTATÍSTICA E DE ESTUDOS SOCIOECONÔMICOS - DIEESE. Anuário do Sistema Público de Emprego, Trabalho e Renda 2010-2011: qualificação social e profissional. 3. ed. São Paulo: Dieese, 2011c. Disponível em: <http://www.dieese.org.br/anu/AnuSistPub2010/conteudo/4/ livro/inicio.html>. Acesso em: 10 jan. 2012.

DEPARTAMENTO INTERSINDICAL DE ESTATÍSTICA E DE ESTUDOS SOCIOECONÔMICOS - DIEESE. Anuário dos trabalhadores: 2010-2011. 11. ed. São Paulo: Dieese, 2011d. Disponível em: <http://www.dieese.org.br/anu/AnuTrab2010/index.html . Acesso em: 10 jan. 2012.

FRANCO, M. C. Formação profissional para o trabalho incerto: um estudo comparativo Brasil, México e Itália. In: Frigotto, G. (Org.). Educação e crise do trabalho: perspectivas de final de século. Petrópolis: Vozes, 1999. p. 100-137.

FRIGOTTO, G. A produtividade da escola improdutiva: um (re) exame das relações entre educação e estrutura econômico-social capitalista. São Paulo: Cortez, 1989.

FRIGOTTO, G. Educação e trabalho: bases para debater a Educação Profissional Emancipadora. Perspectiva, v. 19, n. 1, p. 71-87, jan./jun., 2001.

GENTILI, P. A falsificação do consenso: simulacro e imposição da reforma educacional do neoliberalismo. Petrópolis: Vozes, 1998. 
INSTITUTO BRASILEIRO DE GEOGRAFIA E ESTATÍSITICA - IBGE. Síntese de indicadores sociais: uma síntese das condições de vida da população brasileira - 2010. Rio de Janeiro: IBGE, 2010. Disponível em: <http://www.ibge.gov.br/ home/estatistica/populacao/condicaodevida/indicadoresminimos/sinteseindicsociais2010/SIS_2010.pdf>. Acesso em: 10 jan. 2012.

INSTITUTO Herbert LEVY - IHL. Ensino Fundamental e competitividade empresarial: uma proposta para a ação do governo. São Paulo, 1992.

KUENZER, A. Z. Da dualidade assumida à dualidade negada: o discurso da flexibilidade justifica a inclusão excludente. Educação e Sociedade, v. 28, p. 1153-1178, out. 2007.

OLIVEIRA, R. de. Empresariado industrial e educação brasileira: qualificar para competir. São Paulo: Cortez, 2005.

OliVeIRA, R. de. Agências multilaterais e a educação profissional brasileira. Campinas: Alínea, 2006.

OLIVEIRA, R. de. Educação profissional na Íbero-América: um estudo do programa IBERFOP. Educação \& Realidade, v. 35, n. 3, p. 237-256, set./dez. 2010a.

OLIVEIRA, R. de. O consenso na educação profissional da América Latina. Boletim Técnico do SENAC, v. 36, p. 24-33, set./dez. 2010b.

POCHMANN, M. O emprego na globalização: a nova divisão internacional do trabalho e os caminhos que o Brasil escolheu. São Paulo: Boitempo, 2001.

POCHMANN, M. O emprego no desenvolvimento da nação. São Paulo: Boitempo, 2008.

Recebido: 19/03/2013

Received: 03/19/2013

Aprovado: 24/05/2014

Approved: 05/24/2014 